Social Work Research in the Field of Disability in Australia: A Scoping Review

Christine Bigby*

c.bigby@latrobe.edu.au

Living with Disability Research Centre, La Trobe University, Victoria, Australian

Clare Tilbury

School of Human Services and Social Work, Griffith University, Qld, Australia

Mark Hughes

School of Arts and Social Sciences, Southern Cross University, Qld, Australia.

*corresponding author

Acknowledgements. We acknowledge Dr Lauren Vogel and Dr Lisa Chaffey who provided research assistance with this paper. 


\title{
Social Work Research in the Field of Disability in Australia: A Scoping Review
}

\author{
Abstract \\ While in Australia disability is receiving unprecedented attention with the rollout of major \\ reforms, the body of research on disability to inform policy and practice has been found "not \\ fit for purpose”. This scoping review of empirical research papers published by Australian \\ social work authors between 2007- 2015 investigated the quantity, nature and scope of social \\ work research on disability in Australia. We found a steady growth, an annual average of \\ 13.8 papers, and a total of 124 . Social work disability research makes a distinctive \\ contribution; it is contextualised in service systems or policy, has a greater focus on \\ community and civic participation and social relationships, and concentrates on adults, with \\ either intellectual disability or traumatic brain injury. These research strengths provide \\ foundations for building the profession's research capacity and informing its practice and \\ contribution to the multidisciplinary field of disability.
}

Keywords. Social work research, disability, research impact, evidence based practice 


\section{Social Work Research in the Field of Disability in Australia: A Scoping Review}

People with disability are one of most disadvantaged groups in Australia (National People with Disabilities and Carer Council, 2009), experiencing low rates of economic and social participation, high rates of poverty, abuse, poor health and social exclusion (Bigby \& Frawley, 2010; Australian Bureau of Statistics [ABS], 2013). It is estimated that $18 \%$ of Australians have some form of disability and approximately $6.7 \%$ have a severe or profound disability (ABS, 2013). The proportion of people with a disability is predicted to increase steadily as people with lifelong disability live longer, survival rates of people who acquire a disability in adulthood increase, and age-associated disability rises with population ageing (ABS, 2013; Miller \& Hayward, 2017). Disability is a broad conceptual category that tends to obscure the diversity of those who carry this label in terms of the nature and severity of their impairment. It encompasses people at all stages of the life course and impacts on multiple life domains. People with disability are also part of other populations defined by gender, class, ethnicity, race, sexuality, and place, which in many instances compound the disadvantage they experience as disabled people (Björnsdóttir \& Traustadóttir, 2010).

Since the 1970s, a significant paradigm shift that differentiated impairment and disability has meant a social model of disability replaced individual or medical models. But paradigms co-exist and evolve. The media, for example, continues to portray an individual tragedy model of disability and the Nordic social relational model takes account of both direct impairment effects on the individual and the impacts of social structures (Bigby \& Frawley, 2010; Söder, 2013). During the 1990s, mechanisms such as anti-discrimination laws and disability action plans to remove disabling barriers, and individualised funding to enable people with disability to have greater control over their own support and lives, were introduced. The new directions of marketisation and personalisation in neo-liberal welfare states implemented in the disability sector emphasised consumer choice and control. These 
coalesced with empowerment strategies proposed by the disability rights movement, albeit from a different starting point of consumer rather than citizen rights (van Toorn \& Soldatic, 2015).

In the last decade, Australia has given unprecedented attention to disability policy. Policy reform has had two key planks: the National Disability Strategy [NDS] (Council of Australian Governments, 2011), builds on existing anti-discrimination and human rights legislation to drive equitable access to mainstream services and inclusive communities; and the National Disability Insurance Scheme [NDIS], heralded as the most significant social policy reform since Medicare, which will deliver individualised funding packages to an estimated 460,000 people with severe disabilities under the age of 65 (NDIS, 2013). Funding and progress on the NDS have been slow in contrast to the accelerated rollout of the NDIS from its first trial sites in 2013 to full implementation across Australia by 2019. By this time, it is estimated that funding for disability services will have doubled, amounting to approximately 1.1\% of GDP (Miller \& Hayward, 2017).

Reform on the scale of the NDIS will have major implications for the size and diversity of the disability workforce, creating new opportunities for social workers as planners, local area coordinators, service coordinators, and supervisory or managerial roles in services. Social workers have a long history of working in specialist disability services (Bigby \& Atkinson, 2010). They are likely to occupy a proportion of the $25 \%$ of the disability workforce categorised as managerial and the $8 \%$ categorised as social workers and case managers (Martin \& Healy, 2010). The reach of social work goes well beyond positions in specialist disability services as social workers in other sectors such as health, domestic violence, criminal justice, child and family welfare, education, and housing increasingly encounter people with disability and their families among their clients or communities of interest (Bigby \& Frawley, 2010). 
It has been argued that the values, skills and knowledge base of social work align the profession with rights-based disability policy and the social model (e.g., AASW, 2015; Meekosha \& Dowse, 2007). However, others suggest the relationship between people with disabilities and social workers has not always been empowering, characterising it as "uneasy" (Stainton, Chenoweth, \& Bigby, 2010, p. 1) or “chequered” (Morgan, 2012, p. 221). Disability has also had a low profile in the profession and doubts have been expressed about its preparedness for roles in the NDIS (Bigby, 2013; Soldatic \& Meekosha, 2012).

Developing and delivering effective disability support services and ensuring inclusion in mainstream services requires the use of knowledges from the lived experiences of people with disability and both interdisciplinary and single discipline approaches.

As government embarked on disability policy reform, the significance of disability research and its relative neglect in Australia were recognised (Commonwealth of Australia, 2011), raising questions about from where social workers would draw their knowledge. A National Disability Research and Development Agenda [Agenda] (Commonwealth of Australia, 2011) highlighted broad priorities for disability research and the importance of an inclusive and rights-based approach to directly benefit the lives of people with disabilities. Part of a one-off $\$ 10 \mathrm{~m}$ boost for disability research leveraged by the Agenda was used to commission an audit of Australian disability research to describe its current state and explore gaps [Audit] (Llewellyn, 2014).

The Audit identified 1658 peer reviewed papers published between 2000 and 2013 as well as grey literature. It concluded that this body of research was "not fit for purpose” and augered poorly for evidence-informed policy (Llewellyn, 2014, p.7). The greatest concentrations of research were in the broad domains of health and wellbeing and education, with much less in other domains such as social relationships, community and civic participation. The contribution of social work to disability research could not be identified 
from the Audit. Nonetheless the findings of the few reviews of social work research that have been conducted (Crisp, 2000; Ryan \& Sheehan, 2009) appear to align with the Audit’s conclusion that most research is descriptive or qualitative.

In this study, we aimed to identify Australian social work research in the field of disability in order to compare with the larger body of disability research, and identify research gaps and priorities. This paper is part of a program of work exploring the scope and impact of Australian social work research. It reports the findings of a scoping review on the nature of disability-related social work research in Australia.

\section{Method}

Scoping reviews map the research literature in a particular field, exploring breadth, volume, and characteristics rather than quality (Pham et al., 2014). We used Arksey and O’Malley’s (2005) methodological framework to facilitate rigour and transparency though five stages: identifying the research question, identifying relevant studies, study selection, mapping the data, and collating, summarising the reporting the results (Arksey \& O’Malley, 2005). Our review aimed to answer the research question: what is the quantity, nature, and scope of social work research on disability conducted in Australia?

Inclusion criteria applied to article selection were: peer reviewed journal articles published between 2007 and 2015, written in English, addressing research related to disability. This timeframe was comparable to the other scoping reviews in this program of research (Tilbury, Hughes, Bigby, \& Osmond, 2015; Hughes, Tilbury, \& Bigby, 2016). Books and book chapters were excluded, partly because they are not as easily identifiable, but also because they tend to synthesise rather than report primary research. For similar reasons, journals items such as editorials, commentaries, letters to the editor, along with news 
or magazine articles, and the grey literature were excluded. Non-empirical articles, defined as ones that did not include a method section or present research findings, were also excluded.

Australian research was defined as research conducted in Australia, included Australian participants, or authored by at least one Australian. The definition of disability aligned with the ABS (2013) as any limitation, restriction or impairment that restricts everyday activities for at least six months. We relied on authors' self-definition of their paper as being about disability rather interrogating the definitions each used. This meant, for example, that research on mental illness or chronic illness, which are not generally labelled as disabilities, was unlikely to be included.

Social work research was defined as research with at least one author with social work qualifications. This was determined by their by-lines, information from websites, or online research communities (e.g., ResearchGate). Our primary focus was the corpus of work produced by the social work profession rather than research from other disciplines using what might be regarded as social work frameworks or values.

\section{Search strategy}

Fourteen electronic databases were searched: AMED, Avery, Eric, Informit, Cinahl, Medline, Social Services Abstracts (Proquest), Sociological Abstracts, PsychINFO, Scopus, Current Contents Connect, PubMed, Web of Science, and Google Scholar. Search terms and Boolean phrases included: disability, handicap, mental retardation, developmental disability, intellectual disability, learning disability, learning disorder, brain injury, brain impairment, social work, human services, social care, community services, Australia

\section{Screening and selection}

Figure 1 shows the steps in article selection; 2957 references were sourced from the search. When duplicates were removed, 2265 remained. Examination of the abstracts and titles and 
removal of those not meeting the inclusion criteria left 417 articles. Other articles were removed following review of the full text against the inclusion criteria leaving 130 . Finally, a manual search for social work qualifications of authors left a total of 124 articles.

Insert figure 1 around here

Analysis

Information about each article was entered into an Excel spreadsheet. The conceptual framework adopted by the Audit of disability research was used to code the domains addressed, methods, focus on disadvantaged groups, and environmental/contextual factors (Llewllyn, 2014). Articles were coded for authorship, publication year, journal, primary participants or data source, sub-group of people with disabilities, prominence of social work, and funding source. Once coded, frequencies and percentages were used to summarise the data.

\section{Findings}

\section{Quantity of research}

Most of the 124 papers had multiple authors with an average of 3.4 per paper. Of the 171 different authors, almost a third (53, 31.0\%) had social work qualifications. Although each paper had at least one social work author, only 21.0\% (26/124) were solely authored by social workers. The majority of authors authored only one publication over the 9-year review period (Table 1). Three social work authors accounted for $63.0 \%$ of all the publications: Bigby from La Trobe University (54/124, 43.5\%); Simpson from the Liverpool Brain Injury Rehabilitation Unit (14/124, 11.3\%) and Foster from Griffith University (formerly University of Queensland) (10/124, 8.1\%). These authors sustained significant programs of disability research during the period of the review. Bigby’s publications focused on adulthood and older people with intellectual disability, informal networks of supports, community 
participation, group homes, and the nature of service provision for these groups. Simpson's focused on psycho-social rehabilitation of people with traumatic brain injury, particularly the effectiveness of interventions in acute and community-based rehabilitation services. Similarly, much of Foster's work concerned rehabilitation of people with traumatic brain injury, but with a broader focus on service systems and policy for this group. While few social work authors had 3 or more papers (10/53, 18.9\%) several authors, in addition to Bigby, Simpson, and Foster, have conducted programs of research. For example, Shuttleworth (5) on sexuality and men with intellectual disability, Ellem (6) on social work practice and experiences of offenders, and Chenoweth (6) on lived experiences of people with disability and the nature of service provision.

Insert Table 1 about here

As Table 2 shows, publications by social workers in the field of disability increased steadily, from 6 in 2007 to more than three times that number (21) in 2015. Overall the average number of publications per year was 13.8 .

\section{Insert Table 2 about here}

Papers were published in a range of Australian and international journals (49), categorised on the basis of their title. The largest group of journals had a disability focus (18/49, 36.7\%) and it was in these that the majority of papers (77/124, 62.1\%) were published (Table 3). Most of these journals were multidisciplinary and concerned specific impairment groups, commonly intellectual disability or brain injury. Six journals published almost half the articles (60/124, 48.4\%). Although only one of these was specifically flagged as a social work journal (Australian Social Work, 10/124, 8.1\%), three of the other five included 1607 (Social Work) as one of the Field of Research (FoR) codes used for indexing purposes: Journal of Intellectual and Developmental Disability (21/124, 16.9\%), Journal of Applied Research in 
Intellectual Disabilities (9/124, 7.3\%), and Disability and Society (5/124, 4.0\%). The remaining two of the six top journals Brain Injury (8/124, 6.5\%) and Journal of Intellectual Disability Research (7/124, 5.6\%) were indexed using FoR codes Medical and Health Sciences (1100), Psychology and Cognitive Sciences (1700), and Education (1300).

Insert table 3 about here

A minority of papers (16/124, 12.9\%) were published in seven journals specifically titled as social work, and a further seven journals used the social work FoR 1607 for indexing purposes. The total number of journals therefore in which papers were published that were indexed using the social work FoR code was 14, representing $28.6 \%$ of the 49 journals, but almost half of all the papers identified as having been published during the period of the review $(59 / 124,47.6 \%)$.

Scope of research

Table 4 illustrates the scope of this research, showing the primary focus of each paper utilising the eight domains defined by the Audit. Two domains, health and wellbeing, (34/124, 27.4\%), and community and civic participation (28/124, 22.6\%) accounted for half of all papers, with a further $15.3 \%$ (19/124) encompassing more than two domains. Domains were ranked by number of papers in each as an indicator of their significance to the body of research, and a column added to enable comparison between social work disability research and the Audit findings. As Table 4 shows, apart from health and wellbeing, the pattern of interest differed between the two. Notably social work research appeared to accord greater importance to community and civic participation, a focus across multiple domains, and social relationships compared to the overall body of disability research. The domain of education hardly features in social work disability research compared to its prominence as the second largest in the multidisciplinary Audit. 
Insert Table 4 about here

There was considerable diversity within these domains. For example, included in the category of health and wellbeing were papers on ageing of people with a disability (11), psychological well-being of people with a disability and family members (7), rehabilitation services for people with traumatic brain injury (6), and early intervention services for children with a physical disability (3). Community and civic participation included participation by people with disability in advisory boards, research, and community-based organisations. The domain of social relationships included sexual, family, and staff relationships, as well as those between people with and without disabilities. All but one of the papers on housing were concerned with policy or quality of supported accommodation services for people with intellectual disability. Papers covering more than one domain encompassed disability policy, service models or service systems.

The scope of the research was also examined by sub-groups of people with disability (Table 5). People with intellectual disability were the focus of about half of papers (67/124, 54.0\%) and almost three quarters (89/124, 71.8\%) were concerned with adults. In terms of the disadvantaged groups identified by the Disability Research Agenda, two papers concerned Aboriginal and Torres Strait Islander people and five women with disabilities, with none specifically about people from culturally and linguistic diverse backgrounds or from regional, rural or remote communities. The small number of papers $(10 / 124,8.1 \%)$ that addressed gender-specific issues were equally split between men and women.

\section{Insert Table 5 about here}

Twelve papers focused on cultural and social attitudes, whilst the rest either implicitly or explicitly were concerned with empowering people with disabilities and families through understanding their life experiences, the nature of disability services, or broader service 
systems and policy. No articles explicitly focused on the disabling aspects of physical environments although many examined the poor quality of staff practice and discriminatory social attitudes or policies.

\section{Nature of research}

As Table 6 shows, just over half of all papers (68/124, 54.8\%) were categorised as qualitative, using a variety of data collection methods and research paradigms to explore lived experiences, attitudes, knowledge, or perspectives of participants. Quantitative survey or observational studies were reported in 13 papers (10.5\%). Notably, there was one randomised control trial among the nine intervention studies. Although many papers reported research including people with disabilities as participants, only two reported including them as co-researchers.

Insert Table 6 about here

Table 7 shows the primary study participants or unit of analysis. Individuals were the focus in $20.2 \%(25 / 124)$ of papers, a further $20.2 \%$ focused on the informal and formal network of support around individuals, and 6.5\% (8/124) just on family members of people with disability. Reflecting the finding about the focus on policy, services and systems, almost a third of papers (41/124, 33.1\%) had as the primary unit of analysis the practice of direct support staff, social workers or other professions, or service models. Social work or social workers were the primary unit of analysis for just six papers (4.8\%), including two on social work education, one on the history of social work in disability services, and three on direct social work practice with clients. In terms of the context of the research, an overwhelming majority of papers reported research within support services or service systems (113/124, 91.1\%).

Insert Table 7 about here 


\section{Prominence of social work in research}

An aspect of social work was the explicit focus on nine papers (7.3\%) (Table 8). Three of these concerned direct practice, one disability policy, two field education, two research methods, and one the history of social work's involvement in disability. Notably, four of these papers were included in the 2010 special issue of Australian Social Work on disability policy and practice. Nine papers (7.3\%) included social workers among the participants as well as other professionals and reported on their role in the provision of services separately from that of other professionals, and fifteen (12.1\%) mentioned concepts or values of social work, or social workers as one of the discipline groups either involved in the service under investigation or for whom the findings might be relevant. A word search of every paper identified that 91 (73.4\%) did not mention social work at all other than in the affiliations of the authors.

Insert Table 8 about here

\section{Source of funding}

No source of funding could be identified for over a third of articles (45/124, 36.3\%). As Table 9 shows, 43 papers (34.7\%) reported research funded by nationally competitive research grants, including 31 papers (25.0\%) by the Australian Research Council (ARC), 2 by the National Health and Medical Research Council (NHMRC) and 10 by Australian postgraduate awards. Twenty-four articles (19.4\%) reported funding from a state or federal government department and 9 (7.3\%) from a disability or human service organisation.

Insert Table 9 about here

\section{Discussion}


This scoping review identified 124 disability-related research papers published by authors with social work qualifications between 2007 and 2015. A steady growth of disability-related social work research was illustrated by a tripling in the average annual number of papers. Such growth reflects the trend found by the Audit and indicates heightened interest in disability policy and service systems in Australia during the last decade. Nevertheless, this is a relatively small body of social work research with an annual average output of 13.8 papers. It is smaller than the annual average output in the child protection field of 18.6 papers and comparable to the average of 14.4 papers in the field of aged care (Tilbury et al., 2015; Hughes et al., 2016). Similar to these two fields a majority of social work authors published one paper and there appeared to be few sustained programs of research.

The available data suggest that much social work research is applied in nature and strongly connected to industry. This bodes well for the current government's National Innovation and Science Agenda (Commonwealth of Australia, 2015) that promotes strong connections between research and industry. Not so positive are the small number of postgraduate awards, suggesting only a few higher degree by research students enter this field.

Although only a very small proportion of disability research authored by social workers mentioned the profession or role of social workers, almost half was published in journals indexed with the social work FoR code. One reason might be that social work authors use social work paradigms, frameworks or values without a specific focus on the discipline per se. The findings about place of publication, research design, methods and scope suggest a particular focus on the effectiveness of disability support services, service systems and policy as well as the experiences of people with disability and their families and significant others. The dominance of qualitative methods suggests that like much of the overall body of disability research, social work research contributes to describing the 
"problem”: drawing attention to the disadvantaged position of people with disabilities and service inadequacies. A small number of studies were explanatory, testing the efficacy of interventions or evaluating service models. There were however, some indications from recent publications and funding successes that, having laid out the problems, some of the leading disability social work researchers are embarking on more explanatory approaches (e.g., Bigby, Douglas, Carney, Wiesel, \& Then, 2015). In light of the comment by the Audit that research is urgently needed that can "determine what works and in what settings" (Llewellyn, 2014, p.8) it will be important that social work researchers maintain this growing momentum towards research that tests interventions, program models or evaluates policy initiatives.

Overall this body of research aligns well with the breadth of social work practice and the purpose of social work research as understanding social problems, improving practice in human services, developing equitable social policy, and empowering service users and carers (Orme \& Powell, 2008). Notably, it draws on a social relational model with potential to inform multiple modes of social work practice, from work with individuals to improve health and functioning to addressing program design and broader enablers of community participation. Remarkably similar to the broader body of Australian disability research, social work disability research neglects gender, Aboriginal and Torres Strait Islander people, rural and remote issues and participatory methods. One reason maybe the ethical and resource challenges of researching with rather than about people with a disability. However, this should be an important direction for social work research in the future, especially given the strengths and value base of the profession in working with disadvantaged groups and service users.

Social work disability research forms a relatively small proportion of all Australian disability research, which has an annual output of 127.5 papers (Llewellyn, 2014). It pays 
less attention to education or economic issues and most is contexualised in service systems or policy. It is heavily concentrated on adults, and in two specific sub-groups: those with intellectual disability or traumatic brain injury. Characterised by cognitive disability, these groups are the most marginalised of people with a disability, neglected by both the disability rights movements and critical disability study theorists (Goodley, 2014). Yet their cognitive impairment poses complex challenges to their exercise of rights, choice, and decision-making (Douglas, Bigby, Knox, \& Browning, 2015). They represent a high-needs group, comprising about $60 \%$ of NDIS individually-funded participants. As frequent users of rehabilitation and specialist disability services, they require skilled application of theory to practice, both in terms of direct clinical practice and facilitating community inclusion. The social work research with these groups provides strong foundations for meeting the challenge posed by the expansion of disability services and the search for better evidence to inform policy and practice.

A high proportion of social work researchers co-published with authors from other disciplines, reflecting the multi-disciplinarity of policy and practice. Similar to aged care and health, the audience for social work disability research comprises professionals from various disciplines as well as direct care workers. Remarkably, almost three-quarters of articles did not explicitly connect with the social work profession. This may reflect multidisciplinary research groups or the scope of disability journals but warrants serious consideration by researchers. If social work practitioners and academics cannot easily identify the relevance of disability-related research it is less likely they will use it to inform practice or undergraduate teaching. Researchers must also adopt creative and multiple strategies to disseminate research to foster its utilisation, given the findings of Audit that disability research was inaccessible to audiences who cannot access academic journals. 
The limited social work disability research may also reflect the profession’s neglect of disability as a field of practice (Soldatic \& Meekosha, 2012), its relative absence in social work education, and students' low interest (e.g., Moyle, 2016). There are signs this is changing. The AASW is taking tentative steps to raise social work's profile in the expanding disability/NDIS workforce through publication of a disability scope of practice and discussion of credentialing (AASW, 2016). Moyle (2016) made a strong case for the inclusion of disability as core content in Australian social work curricula requirements. The profession has been directed towards the small but growing field of critical disability studies to find the knowledge for curricula and research necessary to equip social work for disability practice (Meekosha \& Dowse, 2007).

\section{Limitations}

This review captured research published by social workers in journals beyond those that use the FoR code 1607 for indexing and which forms the basis of assessment of social work research in the ARC’s Excellence in Research for Australia. It did not capture research relevant to social work published by authors without social work qualifications. It should be noted that research not directly related to social work may be included in this review when, for example, a social work author is part of a multidisciplinary team. The timeframe for the review also means that the early career publications of longstanding social work disability researchers were not included.

\section{Conclusion}

A concerted set of strategies is necessary to prepare the profession for greater engagement in this growing and complex field of practice and contribute to its knowledge base. Ways must be found to embed parameters for the scope and content of disability-related learning in undergraduate education, promote evidence-informed professional development, and attract 
higher degree research students. To do this an organised and consistent voice is needed to represent the field of disability to AASW and other forums. At present only NSW has an AASW special interest group on disability. Perhaps, a first step is forming a network of social work disability researchers using similar digital strategies to the incipient International Network of Social Workers in Acquired Brain Injury (Simpson, 2017). This may be a means of ensuring that the social work profession is aware of its existing strengths in disability research and injects its voice into the continuing dialogue in Australia about priorities for disability research and building research capacity. The challenge for the $21^{\text {st }}$ century is to build a critical mass of social work research in disability and find ways to ensure it is accessible, well translated with clear implications for policy and practice, and utilised by governments, educators and professionals to further the rights and wellbeing of people with disability and their families.

\section{References}

Arksey, H., \& O’Malley, L. (2005). Scoping studies: Towards a methodological framework. International Journal of Social Research Methodology, 8(1), 19-32.

Australian Association of Social Workers. (2015). Social work practice statement: The contribution social work can make to the national disability insurance scheme. Retrieved from https://www.aasw.asn.au/document/item/7420

Australian Association of Social Workers. (2016) Scope of social work practice - social work in disability. Melbourne: Author

Australian Bureau of Statistics (ABS). (2013). Disability, ageing and carers, Australia: Summary of findings, 2012, Cat 4430.0. Canberra. ABS

Bigby, C. (2013). A National Disability Insurance Scheme: Challenges for social work, Australian Social Work, 66, 1-6. 
Bigby, C., \& Atkinson, D. (2010). Written out of history: Invisible women in intellectual disability social work. Australian Social Work, 63(1), 4-17.

Bigby, C., Douglas, J., Carney, T., Wiesel, I., \& Then, S. (2015). Effective decision making support for people with cognitive disability, Victoria, New South Wales, and Queensland, Australian Research Council, LP150100391.

Bigby, C., \& Frawley, P. (2010). Social work practice and intellectual disability: Working to support change. Basingstoke: Palgrave.

Björnsdóttir, K., \& Traustadóttir, R. (2010). Stuck in the land of disability? The intersection of learning difficulties, class, gender and religion. Disability \& Society, 25, 49-62.

Council of Australian Governments (2011). National disability strategy 2010-2020, Canberra: Commonwealth of Australia.

Crisp, B. (2000). A history of Australian social work practice research. Research on Social Work Practice, 10, 179-199.

Commonwealth of Australia (2011). National disability research and development agenda. Retrieved from https://www.dss.gov.au/disability-and-carers/programsservices/government-international/national-disability-agreement/national-disability$\underline{\text { research-and-development-agenda }}$

Commonwealth of Australia. (2015). National innovation and science agenda. Canberra: Author.

Douglas, J., Bigby, C., Knox, L., \& Browning, M. (2015). Factors that underpin the delivery of effective decision-making support for people with cognitive disability. Research and Practice in Intellectual and Developmental Disabilities, 2, 37-44. 
Goodley, D. (2014). Dis/ability studies: Theorising disablism and ableism: London: Routledge.

Hughes, M., Tilbury, C., Bigby, C. (2016). Australian social work research on ageing and aged care: A scoping review. Journal of Social Work

Llewellyn, G. (2014). Report of audit of disability research in Australia. Sydney: University of Sydney.

Martin, M., \& Healy, J. (2010). Who works in community services? A profile of Australian workforces in child protection, juvenile justice, disability services and general community services. Adelaide: Flinders University.

Meekosha, H., \& Dowse, L. (2007). Integrating critical disability studies into social work education and practice: An Australian perspective. Practice, 19(3), 169-183.

Miller, P., \& Hayward, D., (2017). Social policy “generosity” at a time of fiscal austerity: The strange case of Australia’s National Disability Insurance Scheme. Critical Social Policy, 37, 128-147.

Morgan, H. (2012). The social model of disability as a threshold concept: Troublesome knowledge and liminal spaces in social work education. Social Work Education, 31, 215226.

Moyle, J. (2016). Including disability in the social work core curriculum: A compelling argument, Australian Social Work, 69, 503-511.

National Disability Insurance Scheme Act. (2013). Retrieved from https://www.comlaw.gov.au/Details/C2013A00020

National People with Disabilities and Carer Council. (2009). Shut out: The experience of people with disabilities and their families. Retrieved from https://www.dss.gov.au/. 
Orme, J., \& Powell, J. (2008). Building research capacity in social work: Process and issues. British Journal of Social Work, 38, 988-1008.

Ryan, M., \& Sheehan, R. (2009). Research articles in Australian Social Work from 19982007: A content analysis. Australian Social Work, 62, 525-542.

Soldatic, K., \& Meekosha, H. (2012). Moving the boundaries of feminist social work: Education with disabled people in the neoliberal era. Social Work Education, 31(2), 246252.

Söder, M. (2013) Swedish social disability research: a short version of a long story. Scandinavian Journal of Disability Research, 15, 90-107

Stainton, T., Chenoweth, L., \& Bigby, C. (2010). Social work and disability: An uneasy relationship. Australian Social Work, 63(1), 1-3.

Tilbury, C., Hughes, M., Bigby, C. \& Osmond, J. (in press accepted Sept 2015). Social work research in the child protection field in Australia. British Journal of Social Work.

Tillbury, C., Hughes, M., Bigby, C., \& Fisher, M. (in press accepted August 2016). A comparative study of Australian social work research. British Journal of Social Work.

van Toorn, G., \& Soldatic, K. (2015). Research and Practice in Intellectual and Developmental Disabilities,_2, 109- 115. 
Table 1. Number of publications by author

\begin{tabular}{lcccc}
\hline Number of publications & \multicolumn{2}{c}{ All authors } & \multicolumn{2}{c}{ Social work authors } \\
& $n$ & $\%$ & $n$ & $\%$ \\
\hline 1 & 98 & 57.3 & 34 & 64.2 \\
2 & 35 & 20.5 & 9 & 17.0 \\
3 to 5 & 20 & 11.7 & 2 & 3.8 \\
6 to 9 & 14 & 8.2 & 5 & 9.4 \\
10 or more & & & & \\
Total & 4 & 2.3 & 3 & 5.7 \\
\hline
\end{tabular}


Table 2. Number of publications per year

\begin{tabular}{|c|c|c|}
\hline \multirow[t]{2}{*}{ Year of publication } & \multicolumn{2}{|c|}{ Number of papers } \\
\hline & $n$ & $\%$ \\
\hline 2007 & 6 & 4.8 \\
\hline 2008 & 8 & 6.5 \\
\hline 2009 & 9 & 7.3 \\
\hline 2010 & 11 & 8.9 \\
\hline 2011 & 15 & 12.1 \\
\hline 2012 & 17 & 13.7 \\
\hline 2013 & 15 & 12.1 \\
\hline 2014 & 22 & 17.7 \\
\hline 2015 & 21 & 16.9 \\
\hline Total & 124 & 100.0 \\
\hline
\end{tabular}


Table 3. Journals categorised by title and number of articles in journal category

\begin{tabular}{lcccc}
\hline Category of Journal & Number of journals & \multicolumn{2}{c}{ Number of papers in } \\
& $n$ & & journal category \\
& 18 & 36.7 & 77 & $\%$ \\
\hline Disability & 10 & 20.4 & 12 & 62.1 \\
Policy or community care & 7 & 14.3 & 16 & 12.9 \\
Social Work & 5 & 10.2 & 8 & 6.5 \\
Health & 4 & 8.2 & 4 & 3.2 \\
Social science & 2 & 4.1 & 3 & 2.4 \\
Psychology & 1 & 2.0 & 1 & 0.8 \\
Law & 1 & 2.0 & 1 & 0.8 \\
Occupational Therapy & 1 & 2.0 & 2 & 1.6 \\
Ageing & 49 & 100.0 & 124 & \\
Total & & & & \\
\hline
\end{tabular}


Table 4. Scope of papers by domain and comparison of domain frequency rank with the National Audit of Disability Research

\begin{tabular}{|c|c|c|c|c|}
\hline \multirow[t]{2}{*}{ Domain } & \multicolumn{2}{|c|}{$\begin{array}{c}\text { Number of } \\
\text { papers }\end{array}$} & \multirow[t]{2}{*}{ Rank } & \multirow{2}{*}{$\begin{array}{c}\text { National } \\
\text { audit } \\
\text { rank }\end{array}$} \\
\hline & $n$ & $\%$ & & \\
\hline Health and wellbeing & 34 & 27.4 & 1 & 1 \\
\hline Community and civic & 28 & 22.6 & 2 & 4 \\
\hline \multicolumn{5}{|l|}{ participation } \\
\hline Social relationships & 15 & 12.1 & 4 & 5 \\
\hline Housing and the built & 12 & 9.7 & 5 & 7 \\
\hline \multicolumn{5}{|l|}{ environment } \\
\hline Economic protection and & 4 & 3.2 & 7 & 3 \\
\hline \multicolumn{5}{|l|}{ security } \\
\hline Safety and security & 8 & 6.5 & 6 & 9 \\
\hline Education & 2 & 1.6 & 8 & 2 \\
\hline Transport and communication & 2 & 1.6 & 8 & 8 \\
\hline More than 2 domains & 19 & 15.3 & 3 & 6 \\
\hline Total & 124 & 100.0 & & \\
\hline
\end{tabular}


Table 5. Focus of papers by impairment and life course.

Sub group focus
Number of papers

$n$

\begin{tabular}{lcc}
\hline Impairment $(N=124)$ & 57.0 \\
Intellectual disability & 21 & 16.9 \\
Acquired or traumatic brain injury & 8 & 6.5 \\
Physical disability & 5 & 4.0 \\
Other, stroke, neurological, autism, cognitive & 3 & 2.4 \\
Sensory & 20 & 16.1 \\
Undifferentiated & & 12.9 \\
Life course stage $(N=124)$ & 16 & 71.8 \\
Older adults & 89 & 4.8 \\
Adults & 6 & 10.5 \\
Children & 13 & \\
Undifferentiated & & \\
\hline
\end{tabular}


Table 6. Study design or type of investigation

\begin{tabular}{ll}
\hline Design & Number of papers
\end{tabular}

\begin{tabular}{lcc} 
& $n$ & $\%$ \\
\hline Qualitative study & & 54.8 \\
Quantitative study - survey, observational & 68 & 10.5 \\
Intervention studies, pre-post, single case study, & 9 & 7.3 \\
RCT, matched samples & & \\
Policy analysis & 9 & 7.3 \\
Mixed methods & 7 & 5.6 \\
Program evaluation & 5 & 4.0 \\
Literature review & 5 & 4.0 \\
Measure development & 5.4 \\
Total & 3 & 100.0
\end{tabular}

\footnotetext{
a includes interviews, focus groups using grounded theory, thematic analysis, case study, ethnographic observations
} 
Table 7. Primary participants or unit of analysis

Primary participant or analytical focus

Number of papers

$n \quad \%$

Individual with disability

25

20.2

Network informal and formal support of person with

25

20.2

disability

Direct support staff disability services

14

Professional staff in services, including rehabilitation, aged

care, child welfare, early intervention

8

Service model

13

10.5

Research methods

11

8.9

Family

8

6.5

Social Work including education, policy and direct practice

6

4.8

Literature or data base, primary re individuals with

7

5.6

disability

Policy

7

5.6

Total

124

100 
Table 8. Profile of social work in articles

Profile of social work

Number of papers

$n$

$\%$

Specific focus on social work

9

Inclusion of social workers among participants and specific

9

analysis of role

Mention in passing of social work or social workers as relevant to

15

12.1

the issue, concept, value or one of professionals involved in service

or issue

No mention of social work or social workers

91

73.4

Total

124

100.0 
Table 9. Main funding source

\begin{tabular}{lcc}
\hline Funding source & Number of papers \\
& $n$ & \% \\
\hline Australian Research Council (26 Linkage, & 31 & 25.0 \\
5 Discovery) & 24 & 19.4 \\
Government department & 10 & 8.1 \\
Australian Postgraduate Awards & 9 & 7.3 \\
Non-government disability sector & & 1.6 \\
National Health and Medical Research & 2 & 1.6 \\
Council & 2 & 0.8 \\
Philanthropy & 1 & 36.3 \\
Internal university funds & 45 & 100.0 \\
Not stated & 124 & \\
Total & & \\
\hline
\end{tabular}


Figure 1. Screening and selection of articles

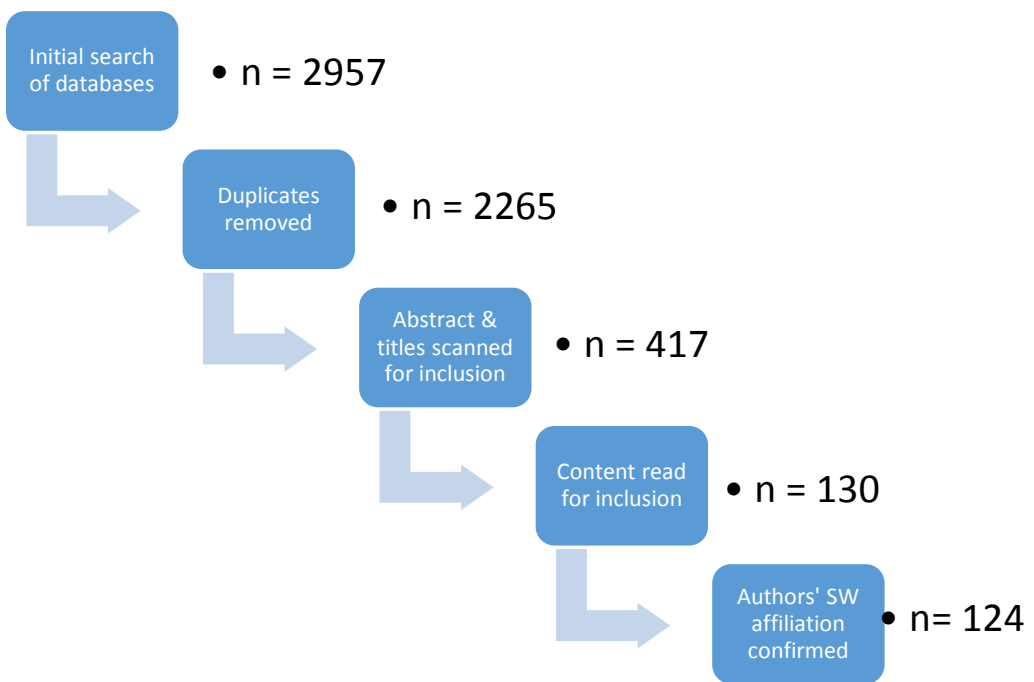

